\title{
Lutando com Dandara de Palmares: feminismos e representatividade na literatura contemporânea
}

\author{
Peleando con Dandara de Palmares: feminismos y representatividad en la \\ literatura contemporánea
}

\author{
Fighting with Dandara de Palmares: feminisms and representativeness in \\ contemporary literature
}

\author{
Maria Laís dos Santos Leite ${ }^{1}$
}

\begin{abstract}
Resumo
As Lendas de Dandara, livro da escritora, cordelista e poeta Jarid Arraes aponta caminhos para ampliar a representatividade feminina e negra em nossa literatura, ao desvelar personagens presentes em nosso cotidiano e até então distantes das estantes das grandes livrarias. O livro é construído a partir da inquietação da pouca visibilidade de mulheres, em especial negras, dentre as personalidades a que se rende homenagens e se refere em nossa história. A obra é composta por dez contos ficcionais sobre a história de Dandara, filha de Iansã, guerreira de Palmares: O nascimento de Dandara; A cura de Bayô; O cavalo roubado; O encontro com Iansã; O navio negreiro; Dandara e Zumbi; Fogo na Casa Grande; Emboscada; Senzalas vazias e A pedreira. Ao contrário de Raízes do Brasil, Casa Grande e Senzala e outros clássicos da historiografia brasileira que nos mostram com um olhar distante os acontecimentos que marcam a exploração e a formação social atual de nosso país, As Lendas de Dandara nos transfere para uma narrativa pessoal e provocadora, que fazia lembrar das narrativas que ouvia sobre nossas ancestrais indígenas e negras, que se perderam nas fugas e cujos traços e estigmas carregamos até hoje. Mulheres que não estavam no rol dos vencedores, dos colonizadores, dos donos de terra, mas das subalternas, das transgressoras. Mulheres cujo corpo não mobilizava cuidado, que capinaram, plantaram, pariram, trabalharam como tantas outras ainda trabalham até hoje, em condições desiguais no Brasil de 2020: escravocrata, racista, misógino, conservador.
\end{abstract}

Palavras-Chave: feminismos; feminismos negros; gênero; literatura brasileira; literatura contemporânea.

\section{Resumen}

As Lendas de Dandara, un libro de la escritora, cordelista y poeta Jarid Arraes, señala formas de expandir la representación femenina y negra en nuestra literatura, al revelar personajes presentes en nuestra vida cotidiana y hasta entonces lejos de los estantes de las grandes librerías. El libro está construido a partir de la inquietud de la baja visibilidad de las mujeres, especialmente las mujeres negras entre las personalidades a las que se rinde homenaje y se hace referencia en nuestra historia. El trabajo consiste en diez cuentos ficticios sobre la historia de Dandara, hija de Iansã, guerrera de Palmares, liberadora de personas que fueron esclavizadas y torturadas: El nacimiento de Dandara; La cura de Bayô; El caballo robado; El encuentro con Iansã; El barco de esclavos; Dandara y Zumbi; Fuego en Casa Grande; Emboscada; Cuartos vacíos de esclavos y La cantera. A diferencia de Raízes do Brasil, Casa Grande y Senzala y otros clásicos de la historiografía brasileña que nos muestran con una mirada distante los eventos que marcan la exploración y la formación social actual de nuestro país, Las Leyendas de Dandara me parecieron reales, provocativas. me recordó las narraciones que escuché sobre mis ancestros indígenas y negros, que se perdieron en las escapadas y cuyos rasgos y estigmas llevamos hoy. Mujeres que no estaban entre los ganadores, los colonizadores, los terratenientes, sino los subordinados, los transgresores. Las mujeres cuyos

\footnotetext{
${ }^{1}$ Doutoranda em Psicologia; Mestra em Desenvolvimento Regional Sustentável; Universidade Federal do Cariri - UFCA/ Universidade Federal do Rio Grande do Norte - UFRN, Natal, Rio Grande do Norte, Brasil; mlaisleite@gmail.com.
} 
cuerpos no movilizaron la atención, que desyerbaron, plantaron, dieron a luz, trabajaron como tantas otras todavía trabajan hoy, en condiciones desiguales en Brasil en 2020, esclavizadas, racistas, misóginas, conservadoras.

Palabras claves: feminismos; feminismos negros; gênero; Literatura brasileña; Literatura contemporánea.

\begin{abstract}
As Lendas de Dandara, a book by the writer, cordelista and poet Jarid Arraes points out ways to expand the female and black representation in our literature, by revealing characters present in our daily lives and until then far from the shelves of large bookstores. The book is built from the uneasiness of the low visibility of women, especially black women among the personalities to whom homage is paid and referred to in our history. The work consists of ten fictional tales about the story of Dandara, daughter of Iansã, warrior of Palmares, liberator of people who were being enslaved and tortured: The birth of Dandara; Bayô's cure; The stolen horse; The encounter with Iansã; The slave ship; Dandara and Zumbi; Fire at Casa Grande; Ambush; Empty slave quarters and The quarry. Unlike Raízes do Brasil, Casa Grande and Senzala and other classics of Brazilian historiography that show us with a distant look the events that mark the exploration and the current social formation of our country, The Legends of Dandara seemed real, provocative, to me it reminded me of the narratives I heard about my indigenous and black ancestors, who were lost in escapes and whose traits and stigmas we carry today. Women who were not on the list of winners, colonizers, landowners, but subordinates, transgressors. Women whose bodies did not mobilize care, who weeded, planted, gave birth, worked like so many others still work today, in unequal conditions in Brazil in 2020, enslaved, racist, misogynist, conservative.
\end{abstract}

Keywords: feminisms; black feminisms; genre; Brazilian literature; contemporary literature.

ARRAES, Jarid. As Lendas de Dandara. São Paulo: Editora de Cultura, 2015, 125 páginas.

\title{
1. Introdução
}

Depois de semanas imersa em um trabalho sobre a questão agrária e a agricultura no Brasil, temática que compõe minha tese de doutoramento, retomo as leituras dos livros nãoacadêmicos, que eu havia colocado no topo da lista de metas para 2020: ler mais literatura, negra, latina, expandir minha capacidade de pensar narrativamente. Nem imaginava que agora era essa meta que ia me permitir vagar por outras trilhas, conhecer novos destinos (inclusive em mim mesma), tirar os pés do chão!

As Lendas de Dandara já me agradava logo de início, a capa ilustrada por Aline Valek traz a representação de uma mulher negra, com armas em punho e feição sisuda já anuncia que saíremos do lugar comum. O livro da escritora, cordelista e poeta Jarid Arraes ${ }^{2}$ aponta caminhos para ampliar a representatividade feminina e negra em nossa literatura, ao desvelar personagens presentes em nosso cotidiano e até então distantes das estantes das grandes livrarias.

O livro é construído a partir da inquietação da pouca visibilidade de mulheres, em especial, negras dentre as personalidades a que se rende homenagens e se refere em nossa história. Arraes (2015) afirma em seu livro que ficou curiosa e sentiu "[...] a necessidade de conhecer mulheres negras que pudessem servir de inspiração e espelhos [...]. Assim iniciou uma pesquisa sobre Dandara, mas "o material a seu respeito era muito escasso e de difícil acesso" e concluiu que:

se Dandara não está devidamente registrada na historiografia brasileira, o machismo e o racismo tão impregnados na nossa cultura certamente

\footnotetext{
${ }^{2}$ Para saber mais sobre autora, conhecer suas obras e adquiri-las acesse: http://jaridarraes.com/.
} 
tiveram papéis importantes nesse enredo. Decidi então encarar a ideia das lendas como uma provocação e uma oportunidade. Pensei comigo mesma: se Dandara é uma lenda, alguém precisa escrever suas lendas. E foi assim que tive a ideia de escrever um livro de ficção, inspirado na história do Brasil e naquilo que sabemos sobre a líder quilombola (p. 8, grifo nosso).

Para escrever As Lendas de Dandara, eu trouxe elementos de fantasia - meu gênero predileto de ficção - e busquei a valorização das religiões de matriz africana, fazendo com que Iansã fosse a responsável pela criação de Dandara. Tomei a liberdade para criar um nascimento poético e misterioso, algo que fizesse total sentido com as poucas informações que temos sobre Dandara, já que não se sabe ao certo onde Dandara nasceu e como foi parar em Palmares. Essa foi a oportunidade perfeita para inserir uma narrativa lendária e mágica.

A obra é composta por dez contos ficcionais sobre a história de Dandara, filha de Iansã, guerreira de Palmares, libertadora de pessoas que estavam sendo escravizadas e torturadas: $\mathrm{O}$ nascimento de Dandara; A cura de Bayô; O cavalo roubado; O encontro com Iansã; O navio negreiro; Dandara e Zumbi; Fogo na Casa Grande; Emboscada; Senzalas vazias e A pedreira.

Ao contrário de Raízes do Brasil, Casa Grande e Senzala e outros clássicos da historiografia brasileira que nos mostram com um olhar distante os acontecimentos que marcam a exploração e a formação social atual de nosso país, As Lendas de Dandara me parecia real, provocador, me fazia lembrar das narrativas que ouvia sobre minhas ancestrais indígenas e negras, que se perderam nas fugas e cujos traços e estigmas carregamos até hoje. Mulheres que não estavam no rol dos vencedores, dos colonizadores, dos donos de terra, mas das subalternas, das transgressoras. Mulheres cujo corpo não mobilizava cuidado, que capinaram, plantaram, pariram, trabalharam como tantas outras ainda trabalham até hoje, em condições desiguais no Brasil de 2020, escravocrata, racista, misógino, conservador. Mulheres a quem nunca foi oferecida ajuda para atravessar à rua ou subir num carro, como nos dizia Sojourner Truth em 1851.

Diferente dos inertes corpos que em geral carregam tantas indagações e diálogos consagrados na literatura, é o corpo ágil e forte de Dandara que nos leva pela história - escrita assim mesmo, porque a narração tem mais embasamento e coerência do que as descrições e ilustrações dos livros escolares de história do Brasil a que tive acesso em minha formação básica

Destaco alguns trechos em que Jarid Arraes (2015) se refere ao corpo da guerreira afrobrasileira que empunhava espadas, lutava capoeira e liderava batalhas:

A Dandara que imaginei e que quero que as pessoas conheçam é uma mulher que rompe muitos paradigmas a respeito do que é um corpo de uma guerreira. Fiz questão de que a personagem tivesse o tom de pele bastante escuro e que seu cabelo crespo fosse visto o tempo inteiro. Além disso, dei a ela uma arma muito especial: a Akofena, que simboliza a coragem e o heroísmo da guerreira (p. 10, grifos nossos).

Dandara quase flutuava pelo chão da mata. No seu peito, o coração pulava e batia como um tambor furioso e ritualístico, perfeitamente sincronizado com seus passos, em harmonia com os movimentos do seu corpo (p. 38, grifos nossos).

Dandara não queria assistir o seu maior sonho escorrendo por suas mãos. Porém, quanto mais se perturbava com esses pensamentos e possibilidades, 
mais sentia seu corpo esfomeado pela liberdade dos que apodreciam nos porões das caravelas. (p. 55, grifos nossos).

Dandara ensinava aos guerreiros posições melhores para a luta enquanto aguardavam que a reunião da tarde começasse. A guerreira exibia os músculos rígidos de sua panturrilha quando colocava o peso do seu corpo sobre uma das pernas. (p. 82, grifos nossos).

Como é possível observar pelos exemplos supramencionados a noção de corporeidade da personagem principal é tão completa e complexa que me mobilizou os sentidos e sentimentos, que - com a sensibilidade aflorada pelo distanciamento social em tempos de pandemia - eu corri pelas clareiras, tive a sensação de medo e força ao emaranhar-me na floresta para fugir dos capitães do mato, participei da libertação dos escravos, senti a história do Brasil, do Brasil que eu conheço e trago no corpo.

O Brasil que concentrou riquezas, que desrespeitou as decisões e os saberes dos povos que já habitavam o território, que tem uma das mais desiguais estruturas fundiárias do mundo e que carrega até a contemporaneidade as marcas de um país colonizado que apresenta disparidades abissais em suas condições econômicas, nutricionais, educacionais e de saúde, decorrentes de uma sequência de atitudes políticas e práticas sociais que sustentam ao longo dos anos as iniquidades vivenciadas.

Indico esta leitura à pesquisadoras(es) das diversas áreas do conhecimento, educadoras(es) e não-acadêmicas(os) para que possam, além da excelente narrativa ampliar sua visão a partir de personagens. A partir de tais leituras, de autoras(es) como Jarid Arraes, politicamente posicionadas(os) com marcadores sociais não hegemônicos: latinoamericanas(os), feministas, nordestinas(os), negras(os) é possível conhecer as histórias e estórias do Brasil ou dos Brasis, por outras vozes, outros olhares. Foi impossível concluir esta leitura, sem sentir-me convocada a promover e divulgar obras e artistas brasileiros que rompam com a construção de personagens que não falem de nós, com as(os) quais não nos identificamos!

Além de As Lendas de Dandara, Jarid Arraes é autora dos livros "Redemoinho em dia quente", "Um buraco com meu nome", "Heroínas Negras Brasileiras em 15 cordéis". Mantinha a coluna "Questão de Gênero" na Revista Fórum, é curadora do selo literário Ferina. Atualmente vive em São Paulo-SP, onde criou o Clube da Escrita Para Mulheres e tem mais de 70 títulos publicados em Literatura de Cordel. A autora pela profundidade de suas personagens, a qualidade de sua escrita e a inovação e representatividade que agrega a nossa literatura contemporânea tem obtido crescente reconhecimento no Brasil e no exterior.

\section{Referências}

ARRAES, Jarid. As Lendas de Dandara. São Paulo: Editora de Cultura, 2015. 